\title{
Expression of a constitutively active mutant of heat shock factor 1 under the control of testis-specific $h s t 70$ gene promoter in transgenic mice induces degeneration of seminiferous epithelium ${ }^{\star \star}$
}

\author{
Wiesława Widłak ${ }^{1 凶}$, Konrad Benedyk ${ }^{1}$, Natallia Vydra ${ }^{2}$, Magdalena Głowala $^{1}$, \\ Dorota Ścieglińska $^{1}$, Ewa Małusecka ${ }^{1}$, Akira Nakai ${ }^{3}$ and Zdzisław Krawczyk ${ }^{1}$ \\ ${ }^{1}$ Department of Tumor Biology, Center of Oncology, Maria Sktodowska-Curie Memorial Institute, \\ Gliwice, Poland; ${ }^{2}$ Institute of Biochemistry, NAS of Belarus, Grodno, Belarus; ${ }^{3}$ Department of \\ Biochemistry and Molecular Biology, Yamaguchi University School of Medicine, Ube, Japan
}

Received: 19 November, 2002; revised: 11 February, 2003; accepted: 21 May, 2003

Key words: $h s t 70$ heat shock gene, spermatogenesis, HSF1, apoptosis, transgenic mouse

\begin{abstract}
Heat shock activates in somatic cells a set of genes encoding heat shock proteins which function as molecular chaperones. The basic mechanism by which these genes are activated is the interaction of the specific transcription factor HSF1 with a regulatory DNA sequence called heat shock element (HSE). In higher eukaryotes HSF1 is present in unstressed cells as inactive monomers which, in response to cellular stress, aggregate into transcriptionally competent homotrimers. In the present paper we showed that the expression of a transgene encoding mutated constitutively active HSF 1 placed under the control of a spermatocyte-specific promoter derived from the hst70 gene severely affects spermatogenesis. We found the testes of transgenic mice to be significantly smaller than those of wild-type males and histological analysis showed massive degeneration of the seminiferous epithelium. The lumen of tubules was devoid of spermatids and spermatozoa and using the TUNEL method we demon-
\end{abstract}

\footnotetext{
${ }^{\star}$ A preliminary report on the same subject was presented at the 38th Conference of the Polish Biochemical Society.

This work was mainly supported by a grant from the State Committee for Scientific Research (KBN, Poland) grant 3 P04A 03323 to W.W. and by a grant awarded to Z.K. by the Foundation for Polish Science. Mrs. Vydra was partially supported by the Office of International Affairs of the U.S. National Cancer Institute.

${ }^{\bowtie}$ Corresponding author: Wiesława Widłak, Department of Tumor Biology, Center of Oncology, Maria Skłodowska-Curie Memorial Institute, 44-100 Gliwice, Poland; tel.: (48 32) 278 9669; fax: (48 32) 231 3512; e-mail: wwidlak@io.gliwice.pl
}

Abbreviations: HSF1, heat shock transcription factor 1; HSE, heat shock element; HSP, heat shock protein. 
strated a high rate of spermatocyte apoptosis. The molecular mechanism by which constitutively active HSF1 arrests spermatogenesis is not known so far. One can assume that HSF1 can either induce or repress so far unknown target genes involved in germ cell apoptosis.

Spermatogenesis is a complex developmental program that produces male gametes. Primitive stem cells, called type A spermatogonia, proliferate and at the start of spermatogenesis some of them give rise to a population of type B spermatogonia which in turn differentiate into more specialized cells called spermatocytes. Spermatocytes undergo chromosomal synapsis and genetic recombination before completing two meiotic divisions and give rise to round spermatids. Subsequently, these cells undergo a remarkable morphogenetic transformation to become spermatozoa (reviewed in Parvinen, 1982).

In the majority of mammals male gonads are located outside the main body cavity. Testicular temperature is lower than core body one and its elevation disrupts spermatogenesis, leading to infertility. Pachytene spermatocytes are the most sensitive cells (Chowdhury \& Steinberger, 1970) and even mild prolonged hyperthermia can significantly increase the process of their apoptosis (Lue et al., 1999). Embryo quality is linked to sperm quality (Jannes et al., 1998), therefore germ cells exposed to thermal stress are expected to either develop cytoprotective mechanisms or to induce apoptotic pathways to undergo active elimination.

Somatic cells are protected from thermal insult by inducing a set of heat shock proteins which function as molecular chaperones to maintain proteins in their native folded state, repair or promote degradation of unfolded proteins, as well as to facilitate proper folding of nascent polypeptides (Gething \& Sambrook, 1992). $h s p$ genes are activated during thermal stress by heat shock transcription factor 1. In higher eukaryotes HSF1 is present in unstressed cells as inactive monomers which, in response to cellular stress, aggregate into homotrimers that bind to HSE element composed of conserved nGAAn repeats and acti- vate target $h s p$ genes (reviewed in Satyal \& Morimoto, 1998). Of all $h s p$ genes the $h s p 70 i$ (inducible) ones which belong to the $h s p 70$ multigene family usually display the highest expression level in cells exposed to heat shock.

While in somatic cells the expression pattern of $h s p 70$ genes seems to be similar, in spermatogenic cells these genes are expressed differently. First, in spermatocytes and spermatids highly specific hsp70-related genes are active. The spermatocyte-specific gene is called hst70 in rat (Krawczyk et al., 1987; Wiśniewski, et al., 1990) and hsp70.2 in mouse (Zakeri et al., 1988). In turn, the spermatid-specific gene is called $h s p 70.3$ in rat (Walter et al., 1994) and hsc70t in mouse (Matsumoto \& Fujimoto, 1990).

Second, in spermatocytes and spermatids the induction level of the $h s p 70 i$ genes seems to be much lower than in somatic cells and it has not yet been determined whether the increased level of HSP70i could have any beneficial/protective effect on these cells (reviewed in Dix, 1997). Moreover, in a recent study it has been demonstrated that expression of a mutated form of HSF1 which is constitutively active and able to bind HSE at the physiological temperature could be a major trigger for the induction of spermatocyte and spermatid apoptosis (Nakai et al., 2000). Because the expression of the mutated HSF1 in the study cited above was under the control of the ubiquitous $\beta$-actin promoter it was thus important to find out whether similar degenerative changes of the seminiferous epithelium could be observed if the expression of this HSF1 was restricted predominantly to spermatocytes.

In the present communication we report a preliminary study on the morphological changes in the testes of transgenic mice in which expression of a constitutively active, DNA-binding form of HSF1 was driven by 
the spermatocyte-specific hst70 gene promoter.

\section{MATERIALS AND METHODS}

Transgenic mice. The pHST(3402/D)HSF1 $\Delta$ RD plasmid (Fig. 1) was constructed by inserting the HindIII(-3402)-DraII(-62)

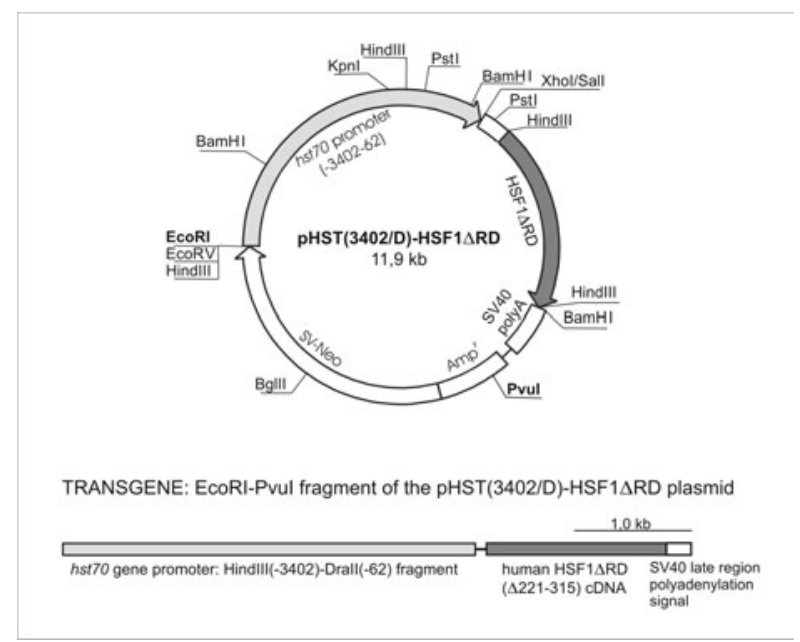

Figure 1. Schematic representation of the pHST(3402/D)-HSF1 $\Delta$ RD transgene.

$\mathrm{Amp}^{\mathrm{r}}$, ampicillin resistance; SV-Neo, neomycin-resistance gene directed by the SV40 early promoter.

fragment of the rat $h s t 70$ promoter (hst70 gene Acc. No. X15705; coordinates of restriction sites refer to A $(+1)$ in the ATG codon), instead of the $\beta$-actin promoter in the parental plasmid which contained the mutant human HSF1 gene encoding a constitutively active form of hHSF1 (deletion of amino acids 221-315 within the regulatory domain; Nakai et al., 2000). Transgenic mice were obtained as described earlier (Widłak et al., 1995). The construct used for microinjection was digested with EcoRI and PvuI restriction enzymes. Appropriate DNA fragment was recovered from agarose gel by electroelution, then purified with Elutip-D (Schleicher \& Schuell), precipitated with ethanol, washed, dissolved in $10 \mathrm{mM}$ Tris/HCl, $\mathrm{pH} 7.4$, and $0.1 \mathrm{mM}$ EDTA, filtered through a $0.02 \mu \mathrm{m}$ Anotop filter and diluted to $1-5 \mathrm{ng} / \mu \mathrm{l}$ for microin- jection. The DNA was microinjected into the pronuclei of zygotes obtained from $\mathrm{FVB} / \mathrm{N}$ females. Transgenic founders were screened by PCR using genomic DNA isolated from tail biopsies and primers complementary to mutant HSF1 sequences (sense: 5'-CCA GCA ACA GAA AGT CGT CA-3'; antisense: $5^{\prime}$-GAG CTC ATT CTT GTC CAG GC-3'). All animal procedures were conforming to institutional regulations and the European regulations concerning the protection animals.

$\boldsymbol{R N A}$ analysis. Total RNA was prepared from testes of control FVB/N and transgenic mice using the guanidine isothiocyanate method (Chomczyński \& Sacchi, 1987). RNA samples were purified from DNA contaminant as described earlier (Ścieglińska et al., 1997). In short, RNA was treated with RNase-free DNase I RQ1 (Promega). Then, aliquots of DNase I-digested samples were additionally treated with RNase A and were used for a control (without template) RT-PCR reaction. The RT-PCR assays were done essentially according to Singer-Sam et al. (1990). At the reverse transcription step the reaction mixture (final volume $50 \mu \mathrm{l}$ ) contained: PCR reaction buffer (Qiagen), $0.2 \mathrm{mM}$ each dNTPs, lower primer $(0.4 \mu \mathrm{M})$, RNA ( $3 \mu \mathrm{g})$, MMLV reverse transcriptase (50 U, Gibco BRL) and Taq polymerase (2 U, Qiagen). Samples were incubated in a thermal cycler (Perkin Elmer, type 3200 ) for $10 \mathrm{~min}$ at $50^{\circ} \mathrm{C}$. Immediately after addition of upper primer $(0.4 \mu \mathrm{M}) 35 \mathrm{cy}$ cles of the PCR reaction were performed $\left(94^{\circ} \mathrm{C}, 30 \mathrm{~s} ; 55^{\circ} \mathrm{C}, 30 \mathrm{~s} ; 72^{\circ} \mathrm{C}, 45 \mathrm{~s}\right)$. RT-PCR products were analyzed on $2 \%$ agarose gel containing ethidium bromide. For $H S F 1 \triangle R D$ transcript amplification the lower primer was 5'-GAG CTC ATT CTT GTC CAG GC-3', and the upper primer was 5'-CCA GCA ACA GAA AGT CGT CA-3' . For hsp70.2 transcript amplification the lower primer was 5'-TCA AGC AAA TCT CCA CGT ACA TAC-3', and the upper primer was $5^{\prime}$-AGG ACC CAC CAT TGA GGA AGT G-3'.

Histopathology. Testes of wild type or transgenic mice were isolated immediately af- 
ter euthanasia by cervical dislocation. For paraffin sections testes were fixed overnight in $10 \%$ buffered formaldehyde at $4^{\circ} \mathrm{C}$, washed three times for $2 \mathrm{~h}$ in phosphate-buffered saline (PBS) at $4^{\circ} \mathrm{C}$, and embedded in paraffin. Embedding solvents and times were as follows: $50 \%$ ethanol for $1 \mathrm{~h}$ at room temperature, $70 \%$ ethanol for $2 \mathrm{~h}, 80 \%$ ethanol for $2 \mathrm{~h}$, $96 \%$ ethanol - overnight, $100 \%$ ethanol three times for $40 \mathrm{~min}$, acetone - for $20 \mathrm{~min}$, xylene - three times for $40 \mathrm{~min}$, paraffin two times for $1 \mathrm{~h}$ at $58^{\circ} \mathrm{C}$, embedding in paraffin at $58^{\circ} \mathrm{C}$. Sections were cut $8 \mu \mathrm{m}$-thick and mounted on glass slides pretreated with poly-L-lysine. They were deparaffinized in xylene, rehydrated in a descending series of ethanol and stained by hematoxylin and eosin. Microscopic analysis was performed with an ECLIPSE E800 Nikon microscope. Pictures were recorded with a Hamamatsu CCD camera and an image analysis system (Lucia).

TUNEL assay. Apoptotic cells were visualized by the terminal deoxynucleotidyl transferase-mediated dUTP nick end-labelling $37^{\circ} \mathrm{C}$ for $60 \mathrm{~min}$. The nuclei of apoptotic cells were stained positive for red fluorescence.

\section{RESULTS AND DISCUSSION}

To achieve testis-specific expression of constitutively active HSF1 we constructed transgenic mice which contained mutated human HSF 1 gene under the control of the hst70 gene promoter. The structure of the $h s t 70$ gene promoter has been under extensive study and the most important DNA regulatory regions conferring testis-specific expression of the gene have been established earlier (Widłak et al., 1994; 1995; Ścieglińska et al., 2001). The structure of the hst70-HSF 1 chimeric gene is shown in Fig. 1. Using routine procedures (Widłak et al., 1995) we obtained three female founders, named TG1, TG2, and TG3 in which the transgene was successfully integrated into genomic DNA. Interestingly, no transgenic males were born. In order to analyze the phenotypic appearance of transgenic males' testes, all female founders were crossed with
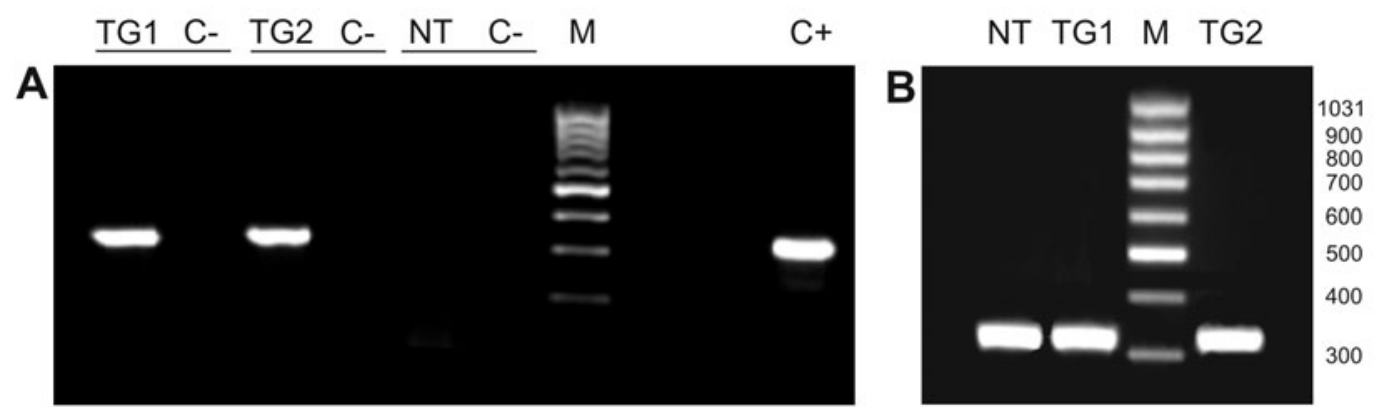

Figure 2. Analysis of expression of the pHST(3402/D)-HSF1 $\Delta$ RD transgene (A) and the endogenous hsp70.2 gene (B) in testes of transgenic (TG) and wild-type mice (NT) by RT-PCR.

M, DNA marker; $\mathrm{C}^{+}$, positive control reaction on plasmid template; C-, negative control reaction.

(TUNEL) assay (Roche). Briefly, testes of wild type and transgenic mice were fixed and embedded in paraffin as described above. Sections were cut $5 \mu \mathrm{m}$ thick, deparaffinized and rehydrated routinely on glass slides. Before performing the TUNEL reaction they were digested for $30 \mathrm{~min}$ at $37^{\circ} \mathrm{C}$ with $20 \mu \mathrm{g} / \mathrm{ml}$ of proteinase $\mathrm{K}$. Then, sections were incubated with $\mathrm{TdT}$ and terminal transferase mixture at
FVB/N males and heterozygotic transgenic males identified by PCR analysis were used for further study. When the transgenic males reached sexual maturity, their testes were excised, weighted, subjected to immunohistochemical analysis and tested for the presence of the transgene transcripts.

Of the three transgenic founders, one (named TG3) gave male progeny with testes 


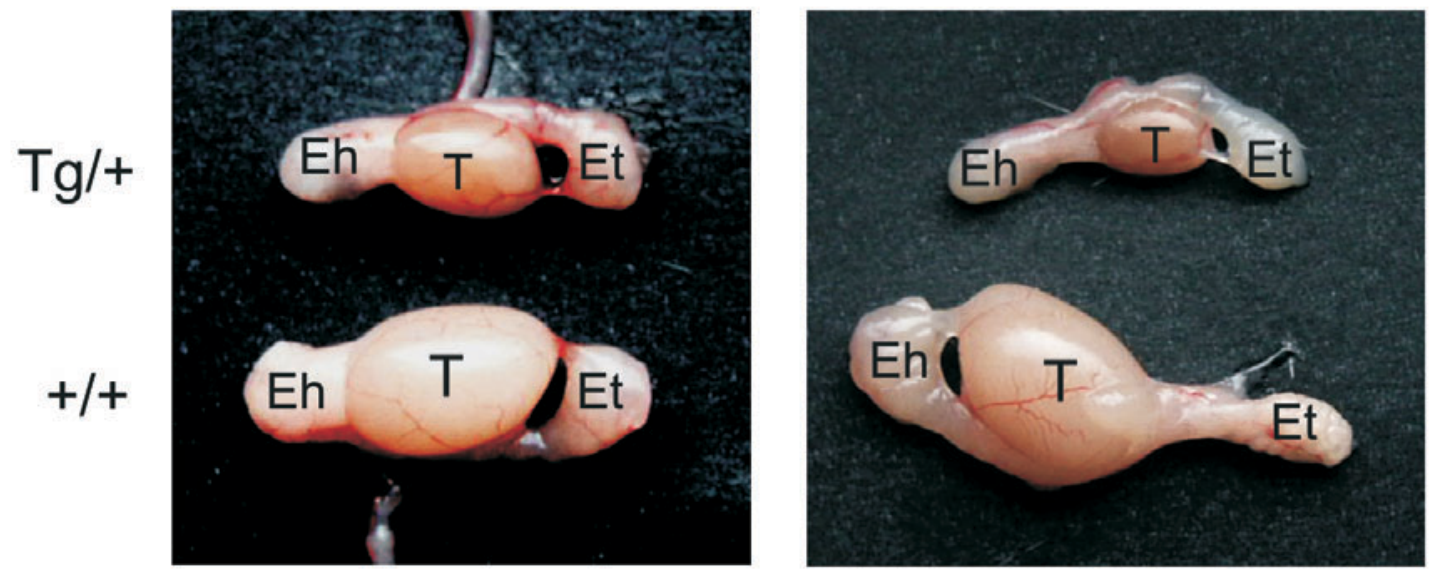

Figure 3. Gross anatomy of the male reproductive organs of 4-month-old wild-type (+/+) and transgenic $(\mathrm{Tg} /+)$ mice from two different founders.

Testis size is reduced in the transgenic mice. T, testis; Eh, head of epididymis; Et, tail of epididymis.

which did not differ in size and weight from those of wild-type mice. However, the testes of the male progeny of the TG1 and TG2 founders in which we detected transcripts of the HSF1 $\triangle R D$ gene (Fig. 2) did not develop normally and their size was strongly reduced as compared to the wild-type mice (Fig. 3). Histological analysis of transgene-positive

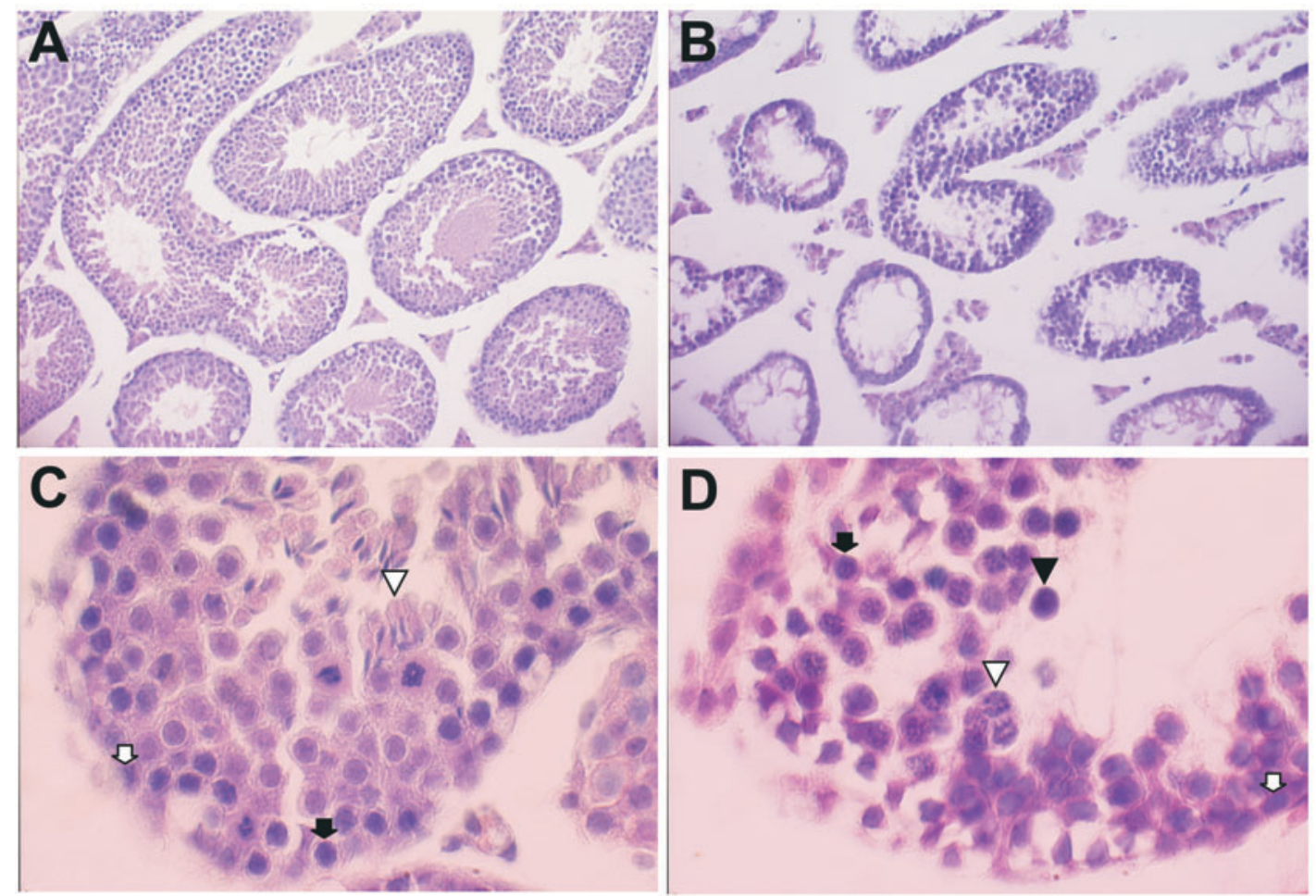

Figure 4. Morphology of seminiferous tubules from 6-week-old wild-type (A, C) and transgenic (B, D) mice.

Tubules of wild-type mouse contain mitotic spermatogonia at the periphery of seminiferous tubules (white arrow), spermatocytes (black arrow), round spermatids and elongating spermatids (arrowhead) being released into the tubule lumen. Seminiferous tubules from transgenic mouse contain mitotic spermatogonia (white arrow) and disorganized mix of pachytene, leptotene/zygotene spermatocytes (black arrow) as well as apoptotic cells with dense nuclei (black arrowhead), vacuoles and giant cells (white arrowhead) but no postmeiotic spermatids or spermatozoa. Diameter of seminiferous tubules in transgene positive mice is reduced. 
males testes showed massive degeneration of the seminiferous epithelium. The epithelium was highly disorganized and giant cells as well as vacuoles, characteristic for the process of degeneration, were present. The lumen of tubules was devoid of spermatids and spermatozoa (Fig. 4) and increased rate of pachytene spermatocyte apoptosis could be seen (Fig. 5). transcription factors (Xie et al., 2002). It seems thus reasonable to assume that HSF1 can either induce or repress, so far unknown, target genes critical for spermatogenesis. The best candidates seem to be genes which are involved in germ cell apoptosis (Matsui, 1998). Hopefully, further investigation shall elucidate whether the activation of heat shock transcription factor 1 could be one of
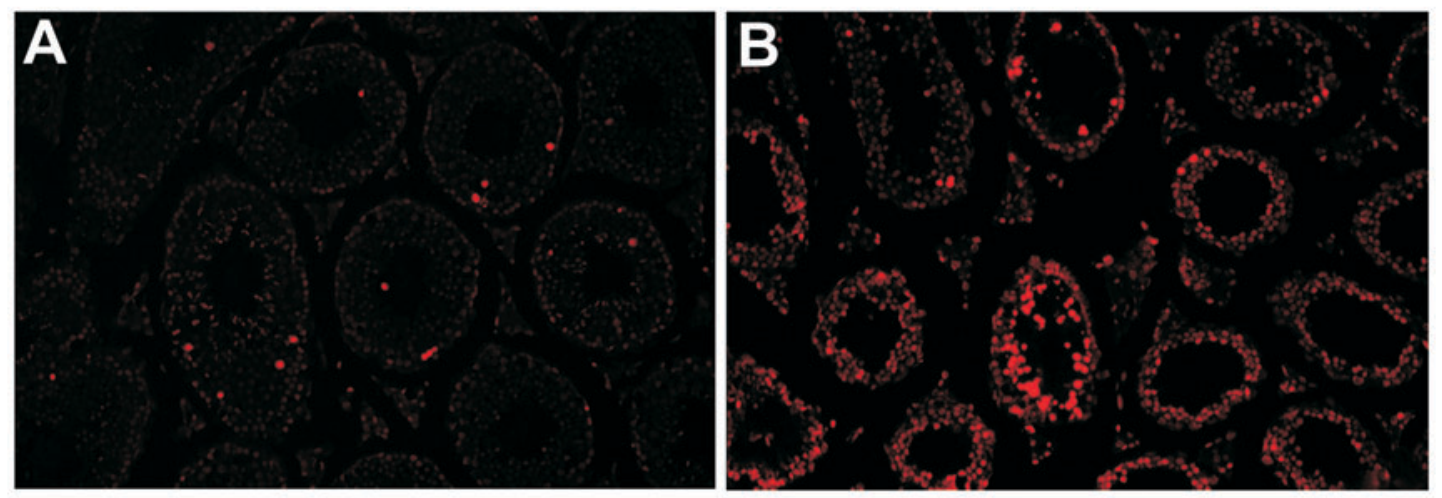

Figure 5. TUNEL detection of apoptotic germ cells in testes of 6-week-old wild type (A) and transgenic (B) males.

Seminiferous tubules in cross-sections of testes from transgene-positive mice contain a cluster of apoptotic cells (red), whereas few apoptotic cells are detected in wild-type mice.

Our data together with the observations of Nakai et al. (2000) strongly suggest that the most probable reason for the HSF1-induced degeneration of the seminiferous epithelium is the expression of this transcription factor in pachytene spermatocytes. In order to determine more precisely the type of cells which are predominantly affected by the HSF1 expression, we are currently studying the morphology of the testes and the rate of spermatogenic cell apoptosis at different stages of the postnatal development of the transgenic males' testes.

The molecular mechanism by which constitutively active HSF1 arrests spermatogenesis at late prophase of the first meiotic division is not known so far. While it is well known that HSF1 can stimulate expression of various genes, some recent studies on somatic cells revealed that HSF1 can also negatively affect expression of certain genes, either by direct binding to HSE-like sequences (Singh et al., 2002) or by binding to other the important causes of heat-induced apoptosis of spermatocytes.

We thank Mrs. K. Klyszcz, Mrs. I. Peick and Mrs. A. Kyrcz for skilful technical assistance and Dr. A. Sochanik for critical reading of the manuscript.

\section{R E F E R E N C E S}

Chomczyński P, Sacchi N. (1987) Single-step method of RNA isolation by acid guanidinium thiocyanate-phenol-chloroform extraction. Anal Biochem.; 162: 156-9.

Chowdhury AK, Steinberger E. (1970) Early changes in the germinal epithelium of rat testes following exposure to heat. J Reprod Fertil.; 22: 205-12.

Dix DJ. (1997) Hsp70 expression and function during gametogenesis. Cell Stress Chaperones.; 2: 73-7. 
Gething MJ, Sambrook J. (1992) Protein folding in the cell. Nature.; 355: 33-45.

Jannes P, Spiessens C, Van der Auwera I, D'Hooghe T, Verhoeven G, Vanderschueren D. (1998) Male subfertility induced by acute scrotal heating affects embryo quality in normal female mice. Hum Reprod.; 13: 372-5.

Krawczyk Z, Wiśniewski J, Biesiada E. (1987) A hsp70-related gene is constitutively highly expressed in testis of rat and mouse. $\mathrm{Mol}$ Biol Rep.; 12: 27-34.

Lue YH, Hikim AP, Swerdloff RS, Im P, Taing KS, Bui T, Leung A, Wang C. (1999) Single exposure to heat induces stage-specific germ cell apoptosis in rats: role of intratesticular testosterone on stage specificity. Endocrinology.; 140: 1709-17.

Matsui Y. (1998) Regulation of germ cell death in mammalian gonads. APMIS.; 106: 142-8.

Matsumoto M, Fujimoto H. (1990) Cloning of a hsp70-related gene expressed in mouse spermatids. Biochem Biophys Res Commun.; 166: $43-9$.

Nakai A, Suzuki M, Tanabe M. (2000) Arrest of spermatogenesis in mice expressing an active heat shock transcription factor 1. EMBO J.; 19: 1545-54.

Parvinen M. (1982) Regulation of the seminiferous epithelium. Endocr Rev.; 3: 404-17.

Satyal SH, Morimoto RI. (1998) Biochemical events in the activation of the heat shock transcriptional response. J Biosci.; 23: 303-11.

Singer-Sam J, Robinson MO, Bellve AR, Simon MI, Riggs AD. (1990) Measurement by quantitative PCR of changes in HPRT, PGK-1, PGK-2, APRT, MTase, and Zfy gene transcripts during mouse spermatogenesis. $\mathrm{Nu}$ cleic Acids Res.; 18: 1255-9.

Ścieglińska D, Widłak W, Rusin M, Markkula M, Krawczyk Z. (1997) Expression of the testis-specific HSP70-related gene (hst70 gene) in somatic non-testicular rat tissues revealed by RT-PCR and transgenic mice analysis. Cell Biol Int.; 21: 813-21.

Ścieglińska D, Widłak W, Konopka W, Poutanen M, Rahman N, Huhtaniemi I, Krawczyk Z. (2001) Structure of the $5^{\prime}$ region of the hst70 gene transcription unit: presence of an intron and multiple transcription sites. Biochem J.; 359: 129-37.

Walter L, Rauch F, Günther E. (1994) Comparative analysis of the three major histocompatibility complex-linked heat shock protein 70 (Hsp70) genes of the rat. Immunogenetics.; 40: 325-30.

Widłak W, Markkula M, Krawczyk Z, Huhtaniemi I. (1994) Functional analysis of spermatocyte- specific hst70 gene promoter in transgenic mice. Acta Biochim Polon.; 41: $103-5$.

Widłak W, Markkula M, Krawczyk Z, Kananen K, Huhtaniemi I. (1995) A 252 bp upstream region of the rat spermatocyte-specific hst70 gene is sufficient to promote expression of the hst70-CAT hybrid gene in testis and brain of transgenic mice. Biochim Biophys Acta.; 1264: 191-200.

Wiśniewski J, Kordula T, Krawczyk Z. (1990). Isolation and nucleotide sequence analysis of rat testis-specific major heat shock (hsp70)-related gene. Biochim Biophys Acta.; 1048: 93-9.

Xie Y, Chen C, Stevenson MA, Auron PE, Calderwood SK. (2002) Heat shock factor 1 represses transcription of the IL-1beta gene through physical interaction with the nuclear factor of interleukin 6. J Biol Chem.; 277: 11802-10.

Zakeri ZF, Wolgemuth DJ, Hunt CR. (1988) Identification and sequence analysis of a new member of the mouse HSP70 gene family and characterization of its unique cellular and developmental pattern of expression in the male germ line. Mol Cell Biol.; 8: 2925-32. 